\title{
A prospective study of maternal factors and perinatal outcome of preterm birth
}

\author{
Kavita Dudhrejia, Zalak V. Karena*, Rahul P. Patel
}

Department of Obstetrics and Gynecology, P. D. U. Medical College, Rajkot, Gujarat, India

Received: 16 November 2019

Accepted: 25 November 2019

\section{*Correspondence:}

Dr. Zalak V. Karena,

E-mail: zalakkarena@gmail.com

Copyright: (C) the author(s), publisher and licensee Medip Academy. This is an open-access article distributed under the terms of the Creative Commons Attribution Non-Commercial License, which permits unrestricted non-commercial use, distribution, and reproduction in any medium, provided the original work is properly cited.

\begin{abstract}
Background: Preterm birth (PTB) is a leading cause of perinatal morbidity and mortality, henceforth being a major concern for the obstetricians and paediatricians as well being a major health care issue. Preventing and treating the associated risk factors could play a major role in curbing the perinatal morbidity and mortality.

Methods: A total 100 women with preterm labour or an indicated preterm termination of pregnancy were enrolled in the study. They were evaluated by history taking, clinical examination, and ultrasonography. Corticosteroids were given to all the patients. Maternal risk factors, obstetric outcome and perinatal outcome till discharge were studied.

Results: Of the 100 women studied, mean age of the cases was 27 years, $60 \%$ of the cases belonged to lower socioeconomic class, $74 \%$ of the cases were under $55 \mathrm{kgs}$ weight group and $77 \%$ of cases were anaemic. $34 \%$ cases were below 34 weeks of gestation, $58 \%$ were multigravida, and $2 \%$ grand multipara with $35 \%$ labour being induced labour because of presence of various risk factors such as preterm premature rupture of membranes (PPROM), preeclampsia, eclampsia and chorioamnionitis. $6 \%$ cases had multiple pregnancies and $8 \%$ had history of preterm delivery in previous pregnancy. Out of 107 babies, $73 \%$ neonates required neonatal intensive care unit (NICU) admission and there was $12.14 \%$ neonatal mortality rate.

Conclusions: Anaemia, malnutrition, infection, high order pregnancy are the preventable causes of preterm birth which can be prevented, screened and treated by specialised antenatal programs.
\end{abstract}

Keywords: Perinatal morbidity, Perinatal mortality, Preterm birth, Preterm labour

\section{INTRODUCTION}

Preterm birth is major public health problem in terms of loss of life, long term disability (cerebral palsy, blindness, deafness, chronic lung disease, gastrointestinal complications) and health care costs both in developing and developed world. Unfortunately, the incidence of preterm labour has changed very little over since long past years, though with a wide part of etiological spectrum being preventable. Timely prediction, prevention and management of preterm labour can improve neonatal outcome and can save a huge portion of health care cost.
Preterm birth is a syndrome with a variety of causes. It is classified into two broad subtypes. (a) Spontaneous preterm birth- Spontaneous onset of preterm labour or following PPROM. (b) Induced/Iatrogenic preterm birthinduction of labour or elective caesarean birth before 37 completed weeks of gestation due to maternal or fetal indications. Preterm labour refers to the onset of uterine contractions of sufficient strength and frequency to effect progressive dilatation and effacement of cervix before 37 weeks of gestation. About 30-35\% of preterm births are indicated for maternal health while $40-45 \%$ and $25-30 \%$ follow spontaneous preterm labour and PPROM respectively. 
Spontaneous preterm birth is thought to be initiated by multiple mechanisms including infections or inflammation, utero-placental ischemia or antepartum haemorrhage (APH) and uterine over-distension. Sociodemographic and obstetric factors have been sought to explain preterm birth and although they do not necessarily imply causation, identifying at-risk women will help initiate risk specific interventions.

The recurrence risk ranges from 17-40\% depending upon the number of previous preterm deliveries. Cervical incompetence, history of one or two first trimester abortions, short interval between the pregnancies $<12$ months have been associated with increased risk of preterm labor. Obstetric and Medical factors like hypertensive disorders of pregnancy increase $12-34 \%$ risk of preterm labour. Renal diseases like acute pyelonephritis, chronic renal disease is also associated with preterm labor. ${ }^{1}$ Heart disease like congenital heart disease and acquired heart disease such as rheumatic heart disease (mitral stenosis and aortic stenosis) increase risk of preterm birth. Infections contribute $17-40 \%$ of preterm deliveries.

Urinary tract infections (UTI), genital tract infections such as gonorrhoea, herpes simplex virus disease, fetotoxic infections such cytomegalo virus disease, toxoplasmosis, listeriosis, maternal systemic infections, maternal intra-abdominal sepsis (appendicitis, cholecystitis) are associated with preterm birth. Remote site infections like periodontitis may cause preterm birth through haematogenous transportation of specific pathogenic organisms or inflammatory cytokines in the ammiotic fluid or chorioamniotic membranes. ${ }^{2}$ Microbiological studies suggest that intrauterine infection might account for $25-40 \%$ of preterm labour where others claim that this can be the minimum estimate because cultures cannot detect all case with intrauterine infection. ${ }^{2}$ Genetic factors like congenital anomalies of the uterus, cervical incompetence, family history of preterm labour are associated with preterm birth. In this study, we aim to analyse the distribution of risk factors of preterm birth in tertiary centre of Gujarat and the burden as well as outcome of preterm births in the institute.

\section{METHODS}

Study is carried out in department of obstetrics and gynecology, at Zanana Hospital and P. D. U. Medical College, Rajkot. 100 women meeting the inclusion criteria were recruited, over a period of 1 year from $1^{\text {st }}$ January 2017 to $31^{\text {st }}$ December 2017. They were evaluated by history taking, clinical examination, and ultrasonography.

\section{Inclusion criteria}

- All women having preterm labour or preterm termination of pregnancy (delivery) were included in the study
- ACOG criteria (1997) were used to document preterm labour and threatened preterm labour - four uterine contractions in 20 minutes with or without cervical dilatation greater than $1 \mathrm{~cm}$ or effacement $80 \%$ or greater

- WHO guidelines were used to label a preterm delivery, which is defined as delivery before 37 completed weeks of gestation.

\section{Exclusion criteria}

- Cases of intrauterine fetal death were excluded from the study.

Before starting enrolment of the participants, necessary clearance and permission were obtained from concerned authorities including Institutional Ethics committee for Human research (IECHR). The participants were enrolled in the study only after taking written informed consent.

Detailed history taking, and general, systemic and obstetrical examinations were done. All women with preterm labour were investigated for presence of infection by complete hemogram, and urine and vaginal swab culture. Antibiotics were provided to those with ruptured membranes or significant pathogen count on urine or vaginal culture. All those with less than 34 weeks of gestation were given $12 \mathrm{mg}$ betamethasone intramuscularly at the time of admission and again after 24 hours. Women were followed up till discharge after delivery.

Risk factors related to preterm birth-social, demographic, medical, obstetric factors were recorded and analysed.

Obstetrical outcome was recorded in terms of gestational age at the time of delivery, duration of labour, mode of delivery, details of perinatal outcome, complications if any. Perinatal outcome was recorded in terms of Apgar score at birth, fetal weight, feto placental ratio, NICU admission and complications in perinatal period.

Results were calculated as the percentage distribution over the assessed factors.

\section{RESULTS}

Our study comprised 100 women who delivered preterm at our hospital. Socio demographic risk factors, obstetric factors, obstetric outcome and perinatal outcome were analysed in detail.

\section{Socio demographic risk factors}

Extremes of age group accounted for $15 \%$ of cases (Table 1) of preterm birth. The mean age in the cases was 27 years. In our study, Kuppuswamy's classification was used to classify women socio economically. $60 \%$ of women with preterm birth were from lower socioeconomic class (Table 2). 
Table 1: Distribution of women according to age.

\begin{tabular}{|lll|}
\hline $\begin{array}{l}\text { Age group } \\
\text { (years) }\end{array}$ & $\begin{array}{l}\text { No. of preterm } \\
\text { labour }(\mathbf{n}=\mathbf{1 0 0})\end{array}$ & $\%$ \\
\hline$<19$ & 7 & $7 \%$ \\
\hline $20-24$ & 33 & $33 \%$ \\
\hline $25-29$ & 36 & $36 \%$ \\
\hline $30-34$ & 16 & $16 \%$ \\
\hline$>35$ & 8 & $8 \%$ \\
\hline
\end{tabular}

Table 2: Distribution of women according to socio economic class.

\begin{tabular}{|l|l|l|}
\hline $\begin{array}{l}\text { Socio-economic } \\
\text { class }\end{array}$ & $\begin{array}{l}\text { No. of preterm } \\
\text { labour }(\mathbf{n = 1 0 0})\end{array}$ & $\%$ \\
\hline Lower & 60 & $60 \%$ \\
\hline Middle & 23 & $23 \%$ \\
\hline Higher & 17 & $17 \%$ \\
\hline
\end{tabular}

Table 3: Distribution of women according to body weight.

\begin{tabular}{|lll|}
\hline $\begin{array}{l}\text { Maternal } \\
\text { weight }(\mathrm{kg})\end{array}$ & $\begin{array}{l}\text { No. of cases } \\
(\mathbf{n}=\mathbf{1 0 0})\end{array}$ & $\%$ \\
\hline$<45 \mathrm{~kg}$ & 19 & $19 \%$ \\
\hline $45-55 \mathrm{~kg}$ & 74 & $74 \%$ \\
\hline$>55 \mathrm{~kg}$ & 07 & $07 \%$ \\
\hline Total & $\mathbf{1 0 0}$ & $\mathbf{1 0 0 \%}$ \\
\hline
\end{tabular}

This shows higher incidence of preterm labour in lower socio-economic class. Table 3 shows distribution of cases as per maternal weight. Here $93 \%$ patient having weight less than $55 \mathrm{~kg}$. $87.4 \%$ patients were having weight less than $55 \mathrm{~kg} .8$ patients having no anaemia (haemoglobin $>10 \mathrm{gm} \%$ ), 77 patients having $\mathrm{Hb} 8-10 \mathrm{gm} \%$ and 15 patients having $\mathrm{Hb}<8 \mathrm{gm} \%$. So, prevalence of anaemia is $92 \%$ among patients having preterm labour (Table 4 ).

Table 4: Association of anaemia and preterm birth.

\begin{tabular}{|ll|}
\hline Haemoglobin level & $\begin{array}{l}\text { No. of anaemic patients } \\
(\mathbf{n}=\mathbf{1 0 0})\end{array}$ \\
\hline$<8$ gm\% & 15 \\
\hline $8-10 \mathrm{gm} \%$ & 77 \\
\hline$>10 \mathrm{gm} \%$ & 8 \\
\hline
\end{tabular}

Table 5: Distribution of women as per parity.

\begin{tabular}{|llll|}
\hline Parity & $\begin{array}{l}\text { No. of cases } \\
(\mathbf{n}=\mathbf{5 8})\end{array}$ & $\begin{array}{l}\text { Percentage } \\
\text { of present } \\
\text { study }\end{array}$ & $\begin{array}{l}\text { Fernandes } \\
\text { SF }^{\text {et } \mathbf{a l}^{5}}\end{array}$ \\
\hline Para 2 & 29 & $50 \%$ & $50.02 \%$ \\
\hline Para 3 & 21 & $36.20 \%$ & $37.67 \%$ \\
\hline Para 4 & 06 & $10.35 \%$ & $8.97 \%$ \\
\hline $\begin{array}{l}\text { Para 5 and } \\
\text { above }\end{array}$ & 02 & $3.45 \%$ & $1.34 \%$ \\
\hline Total & $\mathbf{5 8}$ & $\mathbf{1 0 0 \%}$ & $\mathbf{1 0 0 \%}$ \\
\hline
\end{tabular}

Table 6: Distribution of women according to presence risk factors for preterm birth.

\begin{tabular}{|lllll|}
\hline Risk factors & $\begin{array}{l}\text { No. of cases } \\
(\mathbf{n})\end{array}$ & $\begin{array}{l}\text { Percentage in } \\
\text { present study }\end{array}$ & $\begin{array}{l}\text { Singh U et al } \\
{ }^{7}\end{array}$ & Fernandes SF et al $^{5}$ \\
\hline Active phase of labour (preterm labour) & 65 & $65 \%$ & $68.5 \%$ & - \\
\hline Urinary tract infection & 10 & $10 \%$ & $8.41 \%$ & $13.65 \%$ \\
\hline PPROM & 29 & $29 \%$ & $25.9 \%$ & - \\
\hline Preeclampsia/ eclampsia & 26 & $26 \%$ & - & $21.07 \%$ \\
\hline Ante partum haemorrhage & 8 & $8 \%$ & $10.8 \%$ & $10.9 \%$ \\
\hline Multiple pregnancy & 6 & $6 \%$ & $4.1 \%$ & $9.77 \%$ \\
\hline Polyhydroamnios AFI > 25cm & 4 & $4 \%$ & $3.4 \%$ & $1.46 \%$ \\
\hline Chorioamnionitis & 5 & $5 \%$ & $4.2 \%$ & - \\
\hline GDM & 2 & $2 \%$ & - & $3.41 \%$ \\
\hline Uterine anomaly & 1 & $1 \%$ & $0.7 \%$ & $0.07 \%$ \\
\hline
\end{tabular}

\section{Obstetric factors and obstetric outcome}

Maximum number of women (45\%) were in the gestational age group of 34-36 weeks. In this study, $42 \%$ were primigravida, while the rest were multiparous $(58 \%)$ (Table 5). Among the 58 multiparous women presenting in preterm labour, $29(50 \%)$ were gravid two, 21 $(36.20 \%)$ were gravida three, $6(10.35 \%)$ were gravida four and there were two cases of grand multipara. The study shows that rate of induction is $35 \%$ because of presence of various risk factors such as PPROM, pre- eclampsia, eclampsia, chorioamnionitis, while $65 \%$ women were delivered by spontaneous labour. Among 100 cases of preterm birth, rate of vaginal delivery was $73 \%$ and rate of LSCS was $27 \%$ in the study. Out of 100 women, 95 had singleton pregnancy, 5 were having twin pregnancy and 1 had triplet. The study shows that out of 58 multigravidas, $18(31 \%)$ patients had history of previous one abortion, $13(5.17 \%)$ were having previous two abortions, $1(1.72 \%)$ had past history of previous three abortion and $8(13.79 \%)$ were having history of one preterm vaginal delivery (PTVD). Premature rupture of 
membranes was found to be the most common cause of preterm labour (29\%). Pre-eclampsia and eclampsia accounts for $26 \%$ of cases having incidence of $21.07 \%$ (Table 6).

Table 7: Morbidity in preterm infants.

\begin{tabular}{|llll|}
\hline Morbidity & Case study & $\%$ & $\begin{array}{l}\text { Garg S } \\
\text { et al }^{11}\end{array}$ \\
\hline NICU & 78 & $72.89 \%$ & $84 \%$ \\
\hline $\begin{array}{l}\text { Neonatal } \\
\text { Mortality }\end{array}$ & 13 & $12.14 \%$ & $14 \%$ \\
\hline Jaundice & 34 & $31.77 \%$ & $30 \%$ \\
\hline Asphyxia & 21 & $19.62 \%$ & $18 \%$ \\
\hline RDS & 12 & $11.21 \%$ & $16 \%$ \\
\hline Hypoglycaemia & 3 & $2.80 \%$ & $6 \%$ \\
\hline Septicemia & 5 & $4.67 \%$ & $9 \%$ \\
\hline Hypothermia & 3 & $2.80 \%$ & $12 \%$ \\
\hline $\begin{array}{l}\text { Necrotizing } \\
\text { Enterocolitis }\end{array}$ & 1 & $0.93 \%$ & $1 \%$ \\
\hline
\end{tabular}

\section{Perinatal outcome}

Out of 100 cases studied, 107 babies were under study owing to 6 multiple pregnancies. The study shows that out of 107 babies, $78(72.89 \%)$ neonates required neonatal intensive care unit (NICU) admission and the most common neonatal complications noted were jaundice in $34(31.77 \%)$ neonates, followed by asphyxia $21(19.62 \%)$ and RDS seen in $12(11.21 \%)$ neonates. Hypoglycemia was found in $3(2.80 \%)$ neonates, septicemia was present in $5(4.67 \%)$ neonates, incidence of hypothermia was $2.80 \%$ and NEC found in $1(0.93 \%)$ neonate (Table 7). Neonatal mortality rate was $12.14 \%$ in present study. In present study, birth weight had shown a significant association with mortality as no death was reported in babies born with weight more than 2000 grams (Table 8).

Table 8: Association between birth weight and neonatal mortality.

\begin{tabular}{|c|c|c|c|}
\hline $\begin{array}{l}\text { Weight } \\
\text { (grams) }\end{array}$ & $\begin{array}{l}\text { No. of cases } \\
(n=107)\end{array}$ & Mortality & $\%$ \\
\hline$<1000$ & 7 & 7 & $100 \%$ \\
\hline $1000-1499$ & 27 & 4 & $14.81 \%$ \\
\hline $1500-1999$ & 40 & 2 & $5.0 \%$ \\
\hline$>2000$ & 33 & 0 & $0 \%$ \\
\hline Total & 107 & 13 & - \\
\hline
\end{tabular}

\section{DISCUSSION}

The present study is comparable to study done by Renay Weiner et al in Kenya wherein $18.8 \%$ of cases were in the extremes of reproductive age group. ${ }^{3}$ Maximum patients were from lower socio-economic group. This study is comparable with Fernandes SF et at. ${ }^{4}$ A longitudinal case series examining demographic and obstetric data of 17493 deliveries conducted in a referral centre in Israel preterm delivery rate was much higher in grand multiparas $(93 \%$ among gravid $>5) .{ }^{5}$ Singh et al reports that risk of preterm labour is high in low socioeconomic status, when BMI is less than 19, age is less than 18 and more than 35 , height is less than 140 and weight is less than $50 \mathrm{kgs}^{6}$ Anxiety, stress, depression, long working hours more than 6 hours a day, alcohol, smoking, drug abuse are also associated with preterm birth. Ohmi and others in a retrospective study of 1,194 infants in Japan noted that the risk of preterm birth was significantly increased if mothers smoked during any trimester of pregnancy. ${ }^{7}$ Parazzini et al, in Italy in a case control study demonstrated that moderate prenatal alcohol consumption (> 3 drinks per day) was associated with a significant risk of preterm birth. ${ }^{8,9}$ In our study, in spite of very high incidence of preterm birth amongst teenage patients, the total number of teenage patients was low because of decreasing trend of teenage marriage and late age of marriage. There was significant association of low socioeconomic class, lesser maternal weight and anaemia with preterm birth in our study.

In our institution, with high rate of adoption of methods of family planning methods, percentage of grand multiparas was much lower in the study. Biological factors including previous preterm birth, pre-eclampsia, eclampsia, PPROM and urinary tract infection (UTI) in pregnancy were all significantly associated with preterm birth. PPROM and pre-eclampsia, eclampsia were more strongly associated with preterm birth. Hypertensive disorder of pregnancy was the most common indication for iatrogenic preterm delivery. The higher incidence of hypertensive disorders in our study could be due to the fact that most cases in the present study were referred with no proper antenatal care and the institution is a tertiary care centre which caters to most of high-risk pregnancy.

There was a inverse relationship of neonatal weight with associated neonatal morbidities and mortality. The neonatal mortality rate of the institute was comparable with results of other studies..$^{10-12}$

\section{CONCLUSION}

The perinatal morbidity and mortality rate have played a huge role in changing the plan - how to deliver a preterm baby. Preterm labour and preterm births require early and prolonged hospitalization posing great financial and psychological burden on the family. Most etiological factors are modifiable, and preconception counselling should emphasize family planning, good nutrition, safe sex, good hygiene, treatment of sexually transmitted diseases, and avoidance of tobacco, alcohol, abusive drugs and harmful work conditions. All efforts should be made to prolong the pregnancy beyond 34 weeks for better neonatal outcome. There is need to increase efforts in combating obstetric complications particularly preeclampsia, eclampsia and APH. Health education on the risks posed by high parity, should be emphasized. 
Screening for UTI during the antenatal period should be done regularly and treatment offered promptly when needed. Besides, expert and experienced antenatal care should be given to high risk pregnancies requiring preterm termination of pregnancy, to decide appropriate timing of delivery to avoid unnecessary increase in preterm neonatal morbidities and mortality.

\section{ACKNOWLEDGMENTS}

Authors would like to thank Dr. Kamal Goswami (Head of Department) for his guidance and constant support.

Funding: No funding sources

Conflict of interest: None declared

Ethical approval: The study was approved by the Institutional Ethics Committee

\section{REFERENCES}

1. Pankaj D, Narendra M, Duru S. Principles and practice of obstetrics and gynaecology, $3^{\text {rd }}$ ed; 2008:45-58.

2. Polyzos NP, Polyzos IP, Mauri D, Tzioras S, Tsappi M, Cortinovis I, et al. Effect of periodontal disease treatment during pregnancy on preterm birth incidence: a metaanalysis of randomized trials. Am J Obstet Gynecol. 2009;200(3):225-32.

3. Renay W, Carine R, Ed Dorman, Hilton J, Anne M, Caroline S. Labour complications remain the most important risk factors for perinatal mortality in rural Kenya. Bull World Health Organ. 2003;81:561-6.

4. Shannon F, Savita C. A study of risk factors for preterm labour. Int $\mathbf{J}$ Repro Contracept Obstet Gynecol. 2015;4(5):1306-12.
5. Shlomo E, Ehud W, Zohar N, Eliezer S. Epidemiologic risk factors for preterm delivery. Isr Med Assoc J. 2002;4:1115-7.

6. Singh U, Singh N, Seth S. A Prospective analysis of etiology and outcome of preterm labour. The $\mathbf{J}$ Obstet Gynaecol India. 2007;57:48-52.

7. Ohmi H, Hirooka K, Mochizuki Y. Fetal growth and the timing of exposure to maternal smoking. Pediatr Int. 2002;44:55-9.

8. Parazzini F, Chatenoud L, Surace M, Tozzi L, Salerio B, Bettoni G, et al. Moderate alcohol drinking and risk of preterm birth. Eu J Clin Nutrit. 2003;57(10):1345.

9. Sebayang S, Dibley M, Kelly P, Shanka A, Anuraj H. Determinants of low birth weight, and small-forgestational-age and preterm birth in Lombok, Indonesia: Analysis of the birth weight cohort of the SUMMIT trial. Trop Med Int Health. 2012;17(8):938-50.

10. Garg S, Kaur T, Saran AS, Yadav M. A study of etiology and outcome of preterm birth at a tertiary care centre. Int J Reprod Contracept Obstet Gynecol. 2017;6:4488-91.

11. Satija A, Satija V, Kaur J, Bains HS. Prospective analysis of preterm labour: its etiology and outcome. Int J Basic Appl Med Sci. 2014;4(2):70-7.

12. Sonkusare S, Rai L, Naik P. Preterm birth: mode of delivery and neonatal outcome. Med J Malaysia. 2009;64:303-6.

Cite this article as: Dudhrejia K, Karena ZV, Patel RP. A prospective study of maternal factors and perinatal outcome of preterm birth. Int J Reprod Contracept Obstet Gynecol 2020;9:129-33. 